\title{
Cytotoxicity Evaluation of the East Asian Bullfrog (Hoplobatrachus rugulosus) in an Agricultural Area Affected by Chlorpyrifos
}

\author{
Bundit Tengjaroenkul ${ }^{1,4}$, Somsak Intamat ${ }^{1,3}$, Manop Sriuttha ${ }^{1,6}$, \\ Alongklod Tanomtong ${ }^{1,5}$ and Lamyai Neeratanaphan ${ }^{1,2 *}$ \\ ${ }^{1}$ Research Group on Toxic Substances in Livestock and Aquatic Animals, Khon Kaen University, \\ Khon Kaen 40002, Thailand \\ ${ }^{2}$ Department of Environmental Science, Faculty of Science, Khon Kaen University, Khon Kaen 40002 , \\ Thailand \\ ${ }^{3}$ Thatphanom Crown Prince Hospital, Nakornphanom 48110, Thailand \\ ${ }^{4}$ Department of Veterinary Medicine, Faculty of Veterinary Medicine, Khon Kaen University, \\ Khon Kaen 40002, Thailand \\ ${ }^{5}$ Department of Biology, Faculty of Science, Khon Kaen University, Khon Kaen 40002, Thailand \\ ${ }^{6}$ Faculty of Applied Science and Engineering, Khon Kaen University, Nong Khai Campus, \\ Nong Khai 43000, Thailand
}

Received May 7, 2016; accepted January 18, 2017

\begin{abstract}
Summary This study aimed to investigate chlorpyrifos contamination and chromosome aberrations in H. rugulosus in an affected agricultural area compared to an unaffected area. Five H. rugulosus were collected. Chlorpyrifos concentrations were analyzed with a gas chromatograph equipped with dual capillary columns and a flame photometric detector (GC-FPD). Chromosome aberrations were studied in bone marrow. The average chlorpyrifos concentrations in $H$. rugulosus samples from the agricultural and unaffected areas were $11.43 \pm 7.91$ and $0.31 \pm 0.31 \mathrm{mg} \mathrm{kg}^{-1}$, respectively. The difference in chlorpyrifos concentrations in H. rugulosus samples between the areas was significant $(p<0.05)$. The diploid chromosome number in $H$. rugulosus from both areas was $2 n=26$, and the numbers of chromosome aberrations in H. rugulosus in the agricultural area were higher than those in the unaffected area. There are five types of chromosome aberrations, including single chromatid gap (SCG), single chromatid break (SCB), deletion (D), centric gap (CG), and centric fragmentation (CF). The most common chromosome aberrations in the samples from the affected area were CG. The difference in chromosomal aberrations in H. rugulosus between the areas was significant $(p<0.05)$.
\end{abstract}

Key words Chlorpyrifos, Chromosome aberration, H. rugulosus, Cytotoxic evaluation, Agricultural area.

As the human population increases, the amount of food produced becomes more important (Population Reference Bureau 2015). Thus, agricultural productivity is important for population growth. Unfortunately, other organisms consume crops that are meant for humans. Pesticides are used in agricultural production to prevent or control pests, diseases, weeds, and other plant pathogens in an effort to reduce or eliminate yield losses and to maintain high product quality (Damalas and Eleftherohorinos 2011). Although pesticides benefit farmers, they are also a problem. Pesticide use affects not only farming areas but also adjacent areas (Ardley 1999). Pesticides can spread in the environment and often move through air, soil and water. Pesticides have also been shown to disrupt the balance of ecosystems. In many situations where pesticides are used, they also kill non-pest organisms, which can drastically alter the natu-

\footnotetext{
* Corresponding author, e-mail: hlamya@kku.ac.th

DOI: $10.1508 /$ cytologia. 82.175
}

ral balance of the ecosystem. Additional major problems associated with pesticide use include bioaccumulation and biological magnification. The pesticides that accumulate in an organism's body may harm the organism or may be passed to a predator (Damalas 2009). Organisms that are higher in the food chain will exhibit increased concentrations of pesticides because they consume many lower level organisms and receive the pesticides stored therein.

Thailand is predominantly an agricultural country. A large proportion of the population's livelihood and income derives from the agricultural sector. Large amounts of pesticide are used on farms. The Office of Agricultural Economics, Thailand (2014) found that the amount of pesticide imported during 2010-2014 reached its peak in 2013 and declined in 2014. Most of the imported pesticides were organophosphates, which are highly used among farmers. Organophosphate insecticides, such as diazinon, chlorpyrifos, disulfoton, azinphos-methyl, and fonofos, have been used widely 


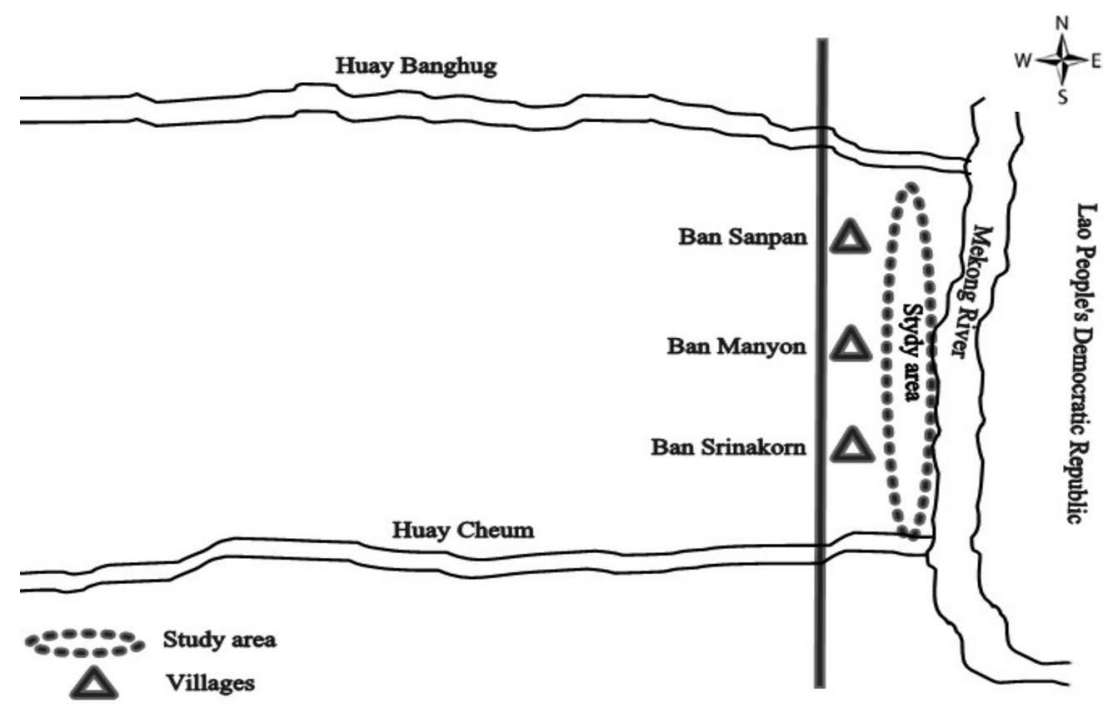

Fig. 1. The location of the sampling collection site is the boundary area.

in agriculture and in household pesticide application. Chlorpyrifos is one of the most widely used organophosphate pesticides in vegetable crops to control pests. Chlorpyrifos has caused genetic damage in human blood and lymphoid cells, mice leukocytes, hamster bone marrow cells, and fish (Rahman et al. 2002, Ali et al. 2008, Cui et al. 2011, Sandal and Yilmaz 2011). Moreover, it can be a cause of cytoxicity in animals (Yin et al. 2009, Ismail et al. 2014).

Amphibians are important model organisms in biology. They are, in most cases, small divers and are sensitive to environmental pollutants because of their permeable skin, larval stage, and unshelled eggs. In addition, they dwell on land and water and eat plants and animals at various life cycle stages (Zhanfen and Xiaobai 2006, Burlibasa and Gavrila 2011). A growing interest in cytotoxicity caused by environmental pollution has led to the development of several biological tests for detecting and identifying cytotoxic agents in air, water, and soil. Frogs are being used as genetic models for the evaluation of pollution in aquatic ecosystems (Zhou et al. 2008, Burlibasa and Gavrila 2011, Ismail et al. 2014).

The Thatphanom district is the most important agricultural area of the Nakornphanom province in Thailand. Tobacco, corn, rice, cabbage, chili pepper, green shallot, yam bean, and other vegetables grow along the Mekong River. These products are exported for sale throughout Thailand. Pesticides are used intensively in this area. In a previous study, Intamat (2011) found that chlorpyrifos is the pesticide used most often by farmers in this area. This study was conducted to determine chlorpyrifos concentrations in $H$. rugulosus samples from agricultural and unaffected areas. In addition, the chromosome aberrations of $H$. rugulosus from the agricultural area were compared to those of $H$. rugulosus from the unaffected area.
Materials and methods

\section{Study areas}

The study site was an agricultural area along the Mekong River, located in the Sanpan sub-district, Thatphanom district, Nakornphanom province of Thailand (Fig. 1). This is a contaminated site characterized by intensive pesticide usage in agricultural areas. Tobacco, corn, rice, cabbage, chili pepper, green shallot, coriander, tomato, and yam bean plants are grown along the Mekong River. An organic agricultural farm located in the Sila sub-district, Muang district, Khon Kaen Province of Thailand, served as a reference site.

\section{Sample collection}

H. rugulosus samples were collected using sweep nets and transferred to properly aerated cages made of wire gauze with floors lined with leaves. Muscles were removed with stainless steel scalpels and forceps, washed in distilled water, and then stored in polyethylene bags and frozen for metal analysis.

\section{Sample extraction and analysis for chlorpyrifos}

Analysis of frog tissue samples with the 1657 A method involved four steps. First, a $10 \mathrm{~g}$ aliquot of a homogenized frog tissue sample was dried with sodium sulfate. Second, a Soxhlet extraction of the dried frog sample was prepared using 1:1 methylene chloride/hexane as the extraction solvent. Third, the extract was dried with sodium sulfate and concentrated until dryness was reached (to measure lipid content) using the KudernaDanish and nitrogen blow-down techniques. Fourth, the extract was re-dissolved, and lipids were removed by gel permeation chromatography and solid phase extraction (SPE cartridges), followed by re-concentration of the extract using the Kuderna-Danish and nitrogen blow-down techniques. Lastly, the target chemicals in the extract 
were quantified using a gas chromatograph equipped with dual capillary columns and a flame photometric detector (GC-FPD) (USEPA 2000).

\section{Chromosome preparation and conventional staining}

H. rugulosus samples were transferred to the laboratory. Chromosomes were directly prepared in vivo (Chen and Ebeling 1968, Nanda et al. 1995) as follows: colchicine was injected into the frog abdominal cavity. After $8 \mathrm{~h}$, bone marrow was cut into small pieces and then mixed with $0.075 \mathrm{M} \mathrm{KCl}$. After all large pieces of tissue were discarded, $7 \mathrm{~mL}$ of cell sediments were transferred to a centrifuge tube and incubated for $10 \mathrm{~min}$. $\mathrm{KCl}$ was discarded from the supernatant after centrifuging again at $2000-2500 \mathrm{rpm}$ for $10 \mathrm{~min}$. The cells were fixed in a fresh, cool fixative (3 methanol:1 glacial acetic acid), which was gradually increased to $7 \mathrm{~mL}$ before centrifuging again at $2000-2500 \mathrm{rpm}$ for $10 \mathrm{~min}$, after which the supernatant was discarded. Fixation was repeated until the supernatant was clear. The pellet was then mixed with $1 \mathrm{~mL}$ of fixative, and the mixture was dropped onto a clean and cold slide using a micropipette, followed by an air-dry technique. Conventional staining was carried out using $20 \%$ Giemsa solution for $30 \mathrm{~min}$ (Rooney 2001).

\section{Chromosome counting and recording of chromosome aberrations}

Chromosome counting and recording of chromosome aberrations were performed on mitotic metaphase cells under a light microscope. One hundred clearly observable cells spread on chromosome plates were selected and photographed. All parameters were followed for karyotyping. Cytotoxicity was evaluated using chromosome aberrations by studying the percentage of chromosome breakages in 100 metaphase cells per individual sample.

\section{Statistical analysis}

Chlorpyrifos concentrations in $\mathrm{H}$. rugulosus and the percentages of chromosome aberrations in the agricultural and unaffected areas were analyzed using the Mann-Whitney $U$-test. All statistical tests were conducted at a $95 \%$ confidence level.

\section{Results and discussion}

\section{Chlorpyrifos concentrations in $\mathrm{H}$. rugulosus samples}

Chlorpyrifos concentrations in H. rugulosus samples from the agricultural and unaffected areas are shown in Table 1. The average chlorpyrifos concentrations in H. rugulosus from the agricultural and unaffected areas were $11.43 \pm 7.91$ and $0.31 \pm 0.31 \mathrm{mg} \mathrm{kg}^{-1}$, respectively. Statistical analysis indicated that there were significant differences between the chlorpyrifos concentrations in H. rugulosus samples from the agricultural and unaf-
Table 1. The chlorpyrifos concentrations in H. rugulosus from the agricultural and unaffected areas.

\begin{tabular}{cc}
\hline \hline H. rugulosus samples & $\begin{array}{c}\text { Chlorpyrifos concentrations } \\
\left(\mathrm{mg} \mathrm{kg}^{-1}\right)\end{array}$ \\
\hline Samples from agricultural area & 6.93 \\
Individual 1 & 7.94 \\
Individual 2 & 15.71 \\
Individual 3 & 3.48 \\
Individual 4 & 23.11 \\
Individual 5 & $11.43 \pm 7.91$ \\
Mean \pm SD & \\
\hline Samples from unaffected area & 0.67 \\
Individual 1 & 0.15 \\
Individual 2 & 0.11 \\
Individual 3 & $0.31 \pm 0.31$ \\
Mean \pm SD & 0.025 \\
\hline$p$-value &
\end{tabular}

fected areas $(p=0.025)$. The highest level of chlorpyrifos in the $H$. rugulosus samples was $23.11 \mathrm{mg} \mathrm{kg}^{-1}$. This may be explained by the fact that $H$. rugulosus was caught after exposure to chlorpyrifos because chlorpyrifos generally has a rapid degradation rate in the environment (Gilani et al. 2010, Hui et al. 2010). Moreover, approximately less than $0.1 \%$ of applied pesticide reaches the target pest, leaving its bulk to contaminate air, water, and soil (Ardley 1999). Chlorpyrifos contaminates H. rugulosus not only through consumption but also through skin exposure (Papadimitriou and Loumbourdis 2003). Furthermore, contaminated sediment and soil particles may be ingested during prey capture (James and Semlitsch 2011). Additionally, most frogs spend several life stages in water as aquatic eggs and larvae, which are more susceptible to environmental pollution because of direct exposure (Burlibasa and Gavrila 2011). Chlorpyrifos contamination in water adversely affects tadpoles. Exposure to chlorpyrifos led to smaller body sizes and delayed maturation in Rana boylii tadpoles (Sparling and Fellers 2009). Moreover, it induces histopathological changes in the gills, liver, and tail of tadpoles of the Duttaphrynus melanostictus species (Bandara et al. 2012). Chlorpyrifos is usually found in agricultural areas and may directly affect aquatic ecosystems. Its presence in water can also affect non-aquatic species via food chains (Maseli et al. 2010, Smalling et al. 2015). In addition, chlorpyrifos caused reversible, concentration-dependent inhibition of the frog noradrenergic junction response to nerve stimulation, possibly due to nonspecific lipid perturbation and protein perturbation, interfering with synaptic transmission and membrane properties (Suwalsky et al. 2003). Therefore, H. rugulosus collected from the agricultural area can pose a health hazard for consumers. However, chlorpyrifos concentrations were noted in $H$. rugulosus from the unaffected area. This may be explained by chlorpyrifos contamination at the other farm near the reference site 
due to the use of pesticides not only in the agricultural area but also in the target area (Ardley 1999).

\section{Chromosome aberrations of $\mathrm{H}$. rugulosus}

This study revealed that the diploid chromosome number $(2 n)$ of $H$. rugulosus from the agricultural and unaffected areas was $2 n=26$. The karyotype of $H$. rugulosus from both areas consisted of eight metacentric and 18 submetacentric regions (Figs. 2 and 3). These data are similar to the data obtained by several studies (Phimphan 2012, Suttichaiya et al. 2016). The different types of chromosome aberrations in the metaphase spread cells of $H$. rugulosus samples from the agricultural area are shown in Fig. 4. The study revealed that the different types of chromosome aberrations were single chromatid break (SCB), centric fragmentation ( $\mathrm{CF})$, deletion
(D), single chromatid gap (SCG), and centric gap (CG). The results of this study were different from a previous study of $H$. rugulosus in a gold mine area with arsenic contamination, which found other types of chromosome aberrations, including isochromatid gap (ISCG), fragmentation (F), isochromatid break (ISCB), and translocation (T) (Suttichaiya et al. 2016). Meanwhile, the types of chromosome aberrations found in Fejervarya limnocharis, which live around municipal landfills, include iso-arm fragmentations (ISAFs) and single chromatid decompose (SCD) (Uraiwan 2016). This may be explained by the types of cytotoxic pollutants to which these organisms are exposed and their toxicities. The numbers and percentages of chromosome aberrations in H. rugulosus samples from the affected and unaffected areas are shown in Table 2. The number of chromo-
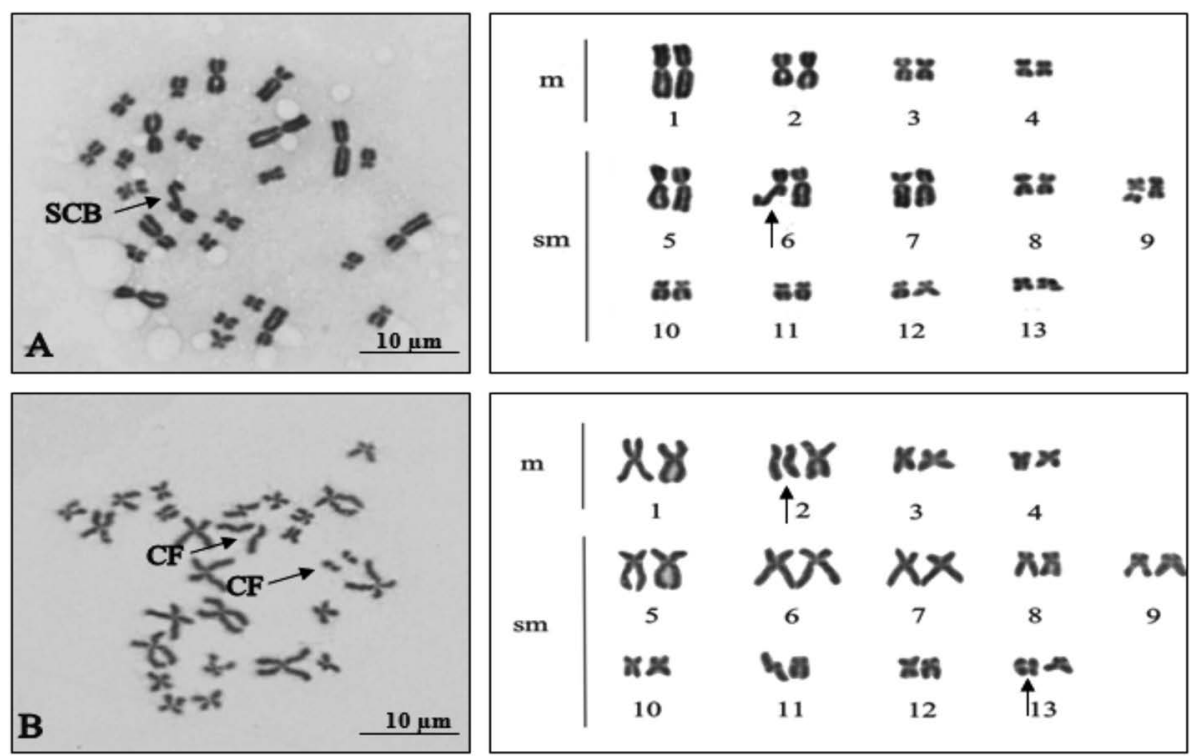

Fig. 2. Metaphase chromosome plates and karyotypes of individual (A, B) H. rugulosus $(2 n=26)$ from the agricultural area using a conventional staining technique. The arrows indicate chromosome aberrations.
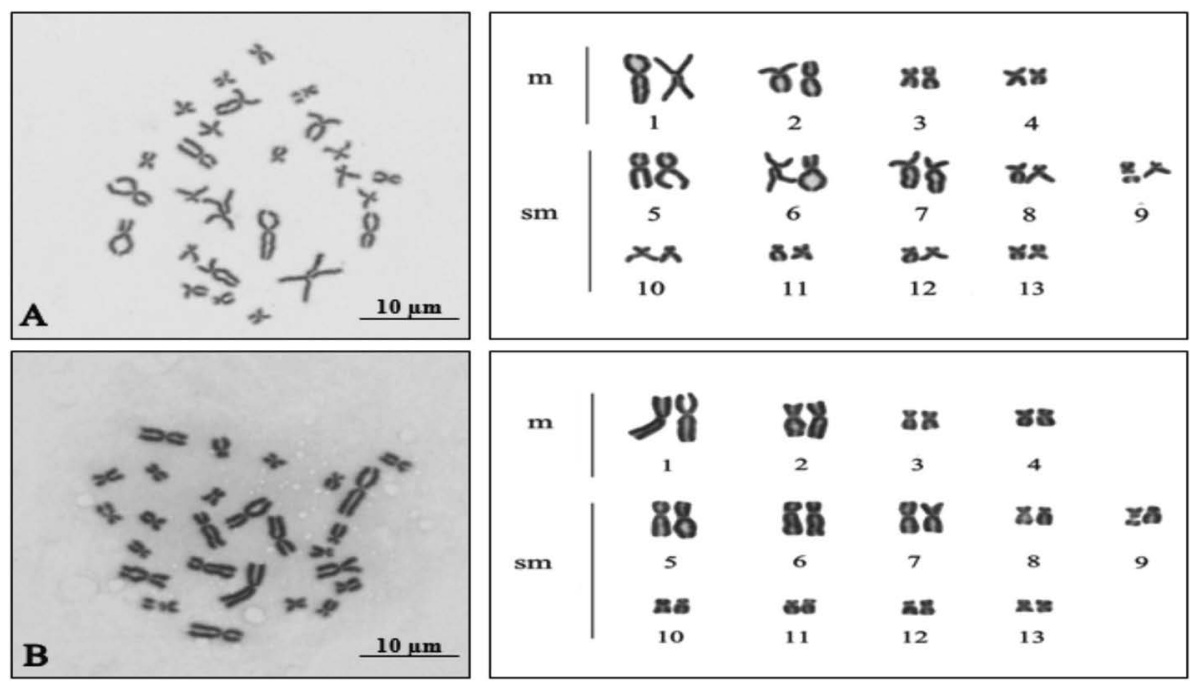

Fig. 3. Metaphase chromosome plates and karyotypes of individual (A, B) H. rugulosus $(2 n=26)$ from the unaffected area using a conventional staining technique. 
some aberrations in $H$. rugulosus samples with respect to SCB, SCG, D, CG and CF were 1,32, 27, 120 and 54 aberrations from the agricultural area and $0,0,0,3$ and 2 aberrations from the unaffected area, respectively. The most common chromosome aberrations in H. rugulosus from the study site were CG. This result was different from those of previous studies. D and $\mathrm{F}$ type chromosome aberrations were found in previous amphibian species studies (Suttichaiya et al. 2016, Uraiwan 2016). Chromosome aberrations represent chromosome macrodamage. There are two types of chromosome aberrations, structural aberrations and numerical aberrations. This study identified structural chromosome aberrations. Chromosome aberrations result from abnormalities in DNA duplication during $\mathrm{S}$ phase. This may be due to the interference of pollutants with nucleotide synthesis (Matter et al. 1992), leading to malformed DNA mol- ecules (Landolt and Kocan 1983). In addition, chromosome aberrations also arise as a consequence of misrepair or misreplication of damaged DNA, the lesions ultimately responsible for DNA strand breaks (Natarajan and Obe 1978, Wong and Dewey 1993). One hundred clearly observable chromosomes were used for this study, and the total numbers of chromosome aberrations found in $H$. rugulosus samples from the agricultural area and from the unaffected area were 234 and 5, respectively. Furthermore, the numbers of cells with chromosome aberrations in H. rugulosus samples from the agricultural and unaffected area were 134 and 5, respectively. Statistical analysis indicates that there were significant differences in the numbers of chromosome aberrations and the numbers of cells with chromosome aberrations between $H$. rugulosus samples from the agricultural and unaffected areas $(p=0.024,0.024)$. The chromo-
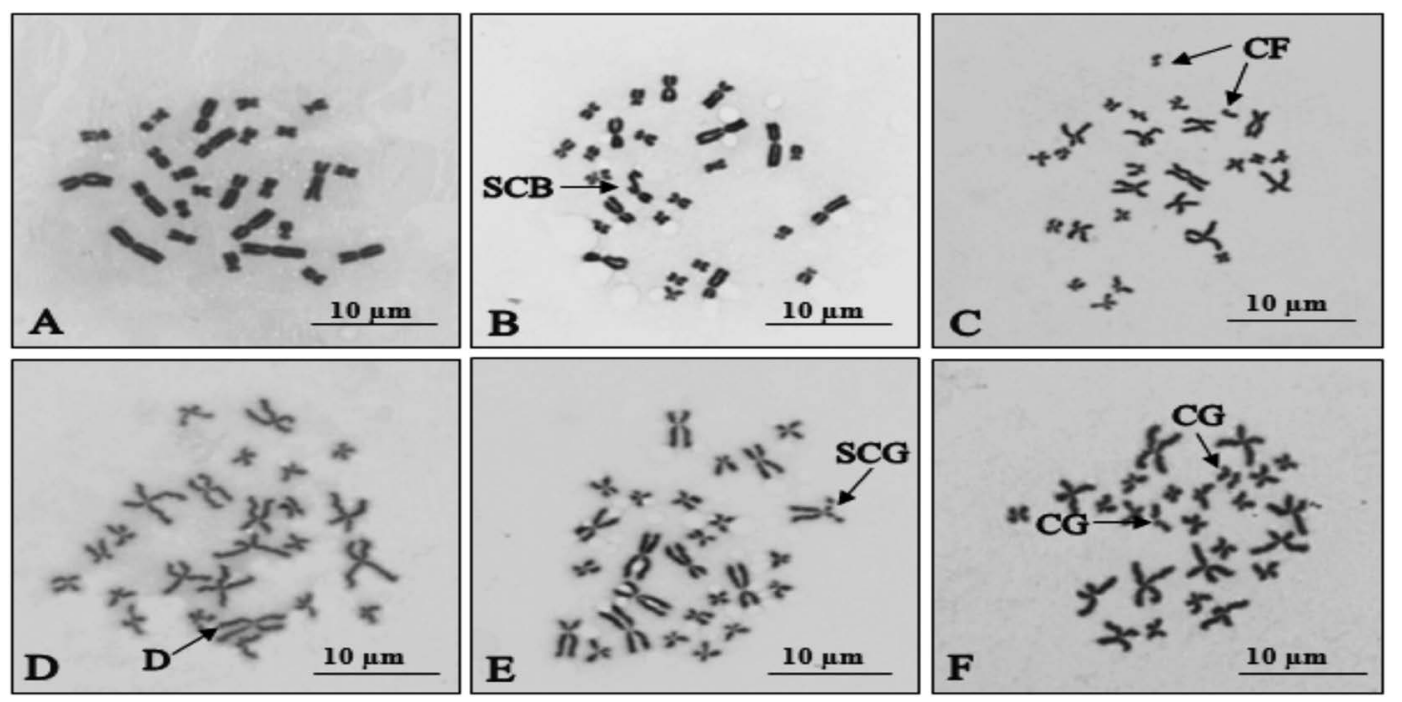

Fig. 4. Different types of aberrations in the metaphase spread of H. rugulosus $(2 n=26)$, showing a single chromatid break $(\mathrm{SCB})$, centric fragmentation (CF), deletion (D), single chromatid gap (SCG), and centric gap (CG) caused by chlorpyrifos (A: Unaffected area, B-F: Agricultural area).

Table 2. Number and percentage of chromosome aberrations in H. rugulosus samples from the agricultural and unaffected areas.

\begin{tabular}{|c|c|c|c|c|c|c|c|c|}
\hline \multirow{2}{*}{ H. rugulosus samples- } & \multicolumn{5}{|c|}{ Number of chromosome aberrations } & \multirow{2}{*}{$\begin{array}{l}\text { Total number of chro- } \\
\text { mosome aberrations }\end{array}$} & \multirow{2}{*}{$\begin{array}{l}\text { Cell number of chromo- } \\
\text { some aberrations }\end{array}$} & \multirow{2}{*}{$\begin{array}{l}\text { Percentage of chromo- } \\
\text { some aberrations }\end{array}$} \\
\hline & $\mathrm{SCB}$ & SCG & $\mathrm{D}$ & CG & $\mathrm{CF}$ & & & \\
\hline \multicolumn{9}{|l|}{ Agricultural area } \\
\hline Individual 1 & 0 & 2 & 2 & 28 & 15 & 47 & 18 & 18 \\
\hline Individual 2 & 0 & 7 & 8 & 17 & 7 & 39 & 26 & 26 \\
\hline Individual 3 & 0 & 12 & 6 & 15 & 3 & 36 & 28 & 28 \\
\hline Individual 4 & 0 & 4 & 4 & 23 & 10 & 41 & 19 & 19 \\
\hline Individual 5 & 1 & 7 & 7 & 37 & 19 & 71 & 43 & 43 \\
\hline Average/Total & 1 & 32 & 27 & 120 & 54 & 234 & 134 & 134 \\
\hline \multicolumn{9}{|l|}{ Unaffected area } \\
\hline Individual 1 & 0 & 0 & 0 & 2 & 1 & 3 & 3 & 3 \\
\hline Individual 2 & 0 & 0 & 0 & 0 & 1 & 1 & 1 & 1 \\
\hline Individual 3 & 0 & 0 & 0 & 1 & 0 & 1 & 1 & 1 \\
\hline Average/Total & 0 & 0 & 0 & 3 & 2 & 5 & 5 & 5 \\
\hline$p$-value & & & & & & 0.024 & 0.024 & \\
\hline
\end{tabular}


some aberrations found in H. rugulosus samples from the agricultural area were also present in samples from the unaffected area. This may be explained by colchicine exposure because colchicine is a mutagenic agent (Arni and Hertner 1997).

\section{Conclusion}

The agricultural area has a high level of pesticide contamination. In this study, chlorpyrifos was determined to be present in $H$. rugulosus. Based on the results of this study, we can conclude that chlorpyrifos exists in aquatic food webs. Moreover, it may be a potential source of risk to human health because local people eat frogs regularly. The average percentage of chromosome aberrations in $H$. rugulosus samples from the agricultural area was higher than that in samples from the unaffected area. Exposure to high concentrations of chlorpyrifos may induce structural chromosome aberrations in $H$. rugulosus without affecting the number of chromosome aberrations. This is a warning signal regarding declining amphibian populations. Therefore, accumulation of chlorpyrifos in H. rugulosus species should be a concern due to its potential effects on human health. The government should be informed of the results of this research so that officials can properly consider the consumption of $H$. rugulosus that live in contaminated areas. Integrated pest management (IPM) should be provided to farmers that need to solve pest problems, while minimizing risks to humans and to the environment.

\section{Acknowledgements}

This research was supported by the Research Group on Toxic Substances in Livestock and Aquatic Animals, Khon Kaen University.

\section{References}

Ali, D., Nagpure, N. S., Kumar, S., Kumar, R. and Kushwaha, B. 2008. Genotoxicity assessment of acute exposure of chlorpyrifos to freshwater fish Channa punctatus (Bloch) using micronucleus assay and alkaline single-cell gel electrophoresis. Chemosphere 7: 1823-1831.

Ardley, J. H. 1999. Pesticide considerations: An environmental concern. Agric. Sci. 12: 21-24.

Arni, P. and Hertner, T. 1997. Chromosomal aberrations in vitro induced by aneugens. Mutat. Res. 379: 83-93.

Bandara, M. G. D. K., Wijesinghe, M. R., Ratnasooriya, W. D. and Priyani, A. A. H. 2012. Chlorpyrifos induced histopathological alterations in Duttaphrynus melanostictus (Schneider 1799) tadpoles: Evidence from empirical trials. J. Trop. For. Env. 2: 27-36.

Burlibasa, L. and Gavrila, L. 2011. Amphibians as model organisms for study environmental genotoxicity. Appl. Ecol. Env. Res. 9: $1-15$.

Chen, T. R. and Ebeling, A. W. 1968. Karyological evidence of female heterogamety in the mosquitofish, Gambusia affinis. Copeia 1: $70-75$

Cui, Y., Guo, J., Xu, B. and Chen, Z. 2011. Genotoxicity of chlorpyri- fos and cypermethrin to ICR mouse hepatocytes. Toxicol. Mech. Methods 21: 70-74.

Damalas, C. A. 2009. Understanding benefits and risks of pesticide use. Sci. Res. Essays 4: 945-949.

Damalas, C. A. and Eleftherohorinos, I. G. 2011. Pesticide exposure, safety issues, and risk assessment indicators. Int. J. Environ. Res. Public Health 8: 1402-1419.

Gilani, S. T. S., Ageen, M., Shah, H. and Raza, S. 2010. Chlorpyrifos degradation in soil and its effect on soil microorganisms. J. Anim. Plant Sci. 20: 99-102.

Hui, T. J., Ariffin, M. M. and Tahir, N. M. 2010. Hydrolysis of chlorpyrifos in aqueous solutions at different temperatures and $\mathrm{pH}$. Malay. J. Analyt. Sci. 14: 50-55.

Intamat, S. 2011. Exposure assessment of organophosphate among chrysantemum growers in Thatphanom subdistrict Thatphanom district Nakornphanom province. Master's Thesis, Department of Environmental Technology, Faculty of Science, Ubon Ratchathani University, Ubon Ratchathani.

Ismail, M., Khan, Q. M., Ali, R., Ali, T. and Mobeen, A. 2014. Evaluation of the genotoxicity of chlorpyrifos in common indus valley toad, Bufo stomaticus using alkaline single-cell gel electrophoresis (Comet). Assay. Agric. Sci. 5: 376-382.

James, S. M. and Semlitsch, R. D. 2011. Terrestrial performance of juvenile frogs in two habitat types after chronic larval exposure to a contaminant. J. Herpetol. 45: 186-194.

Landolt, M. L. and Kocan, R. M. 1983. Fish cell cytogenetics: A measure of the genotoxic effects of environmental pollutants. Aquat. Toxicol. 13: 335-353.

Maseli, V., Polese, G., Rippa, D., Ligrone, R., Rastogi, R. K. and Fulgione, D. 2010. Frogs, sentinels of DNA damage induced by pollution in Naples and the neighbouring Provinces. Ecotoxicol. Environ. Saf. 73: 1525-1529.

Matter, E. E., El-Serafy, S. S., Zowail, M. E. M. and Awwad, M. H. 1992. Genotoxic effect of carbamyl insecticide (sevin) on the grass carp Ctenopharygodan idella (VAL). Egypt. J. Histol. 15: 9-17.

Nanda, I., Schartl, M., Feichtinger, W., Schlupp, I., Parzefall, J. and Schmid, M. 1995. Chromosomal evidence for laboratory synthesis of a triploid hybrid between the gynogenetic teleost Poecilia formosa and its host species. J. Fish Biol. 47: 619-623.

Natarajan, A. T. and Obe, G. 1978. Molecular mechanisms involved in the protection of chromosomal aberrations. Mutat. Res. 52: 137-149.

Papadimitriou, E. A. and Loumbourdis, N. S. 2003. Copper kinetics and hepatic metallothionein levels in the frog Rana ridibunda, after exposure to $\mathrm{CuCl}_{2}$. Biometals 16: 271-277.

Phimphan, S. 2012. Cytogenetics of some amphibians in Khon Kaen University. Master's Thesis, Department of Biology, Faculty of Science, Khon Kaen University, Khon Kaen.

Population Reference Bureau 2015. 2015 World Population Data Sheet. http://www.prb.org/Publications/Datasheets/2015/2015world-population-data-sheet. aspx. (11 April 2016).

Rahman, M. F., Mahboob, M., Danadevi, K., Saleha, B. B. and Grover, P. 2002. Assessment of genotoxic effects of chlorpyrifos and acetaphate by the comet assay in mice leucocytes. Mutat. Res. 516: 139-147.

Rooney, D. E. 2001. Human Cytogenetics: Constitutional Analysis, A Practical Approach. Oxford University Press, London.

Sandal, S. and Yilmaz, B. 2011. Genotoxic effects of chlorpyrifos, cypermethrin, endosulfan and 2,4-D on human peripheral lymphocytes cultured from smokers and nonsmokers. Environ. Toxicol. 26: $433-442$.

Smalling, K. L., Reeves, R., Muths, E., Vandever, M., Battaglin, W. A., Hladik, M. L. and Pierce, C. L. 2015. Pesticide concentrations in frog tissue and wetland habitats in a landscape dominated by agriculture. Sci. Total Environ. 502: 80-90. 
Sparling, D. W. and Fellers, G. W. 2009. Toxicity of two insecticides to California, USA, anurans and its relevance to declining amphibian populations. Environ. Toxicol. Chem. 28: 1696-1703.

Suttichaiya, A., Neerataphan, L., Khammanichanh, A., Patawang, I., Tanamtong, A. and Sriuttha, M. 2016. Chromosome aberrations of east asian bullfrog (Hoplobatrachus rugulosus) around a gold mine area with arsenic contamination. Environment Asia 9: $67-76$.

Suwalsky, M., Benites, M., Norris, B. and Sotomayor, C. P. 2003. The organophosphorous insecticide chlorpyrifos affects the neuroepithelial junction, the bioelectric parameters of the skin of the frog Caudiverbera caudiverbera, and the structure of model cell membranes. Pestic. Biochem. Physiol. 77: 44-53.

The Office of Agricultural of Economics 2014. Pesticide import and use in Thailand. Annual Report, Bangkok.

Uraiwan, P. 2016. Chromosomal aberration assessment of rice field frog (Fejervarya limnocharis) affected by landfill leachate. Mas- ter's Thesis, Department of Environmental Science, Faculty of Science, Khon Kaen University, Khon Kaen.

USEPA 2000. Method 1657, Revision A: Organo-phosphorus pesticides in wastewater, soil, sludge, sediment, and tissue by GCFPD. USEPA, Washington, D.C.

Wong, R. S. and Dewey, W. C. 1993. Molecular mechanisms for the induction of chromosomal aberrations in $\mathrm{CHO}$ cells heated in $\mathrm{S}$ phase. Environ. Mol. Mutagen. 22: 257-263.

Yin, X., Zhu, G., Li, X. B. and Liu, S. 2009. Genotoxicity evaluation of chlorpyrifos to amphibian Chinese toad (Amphibian: Anura) by Comet assay and Micronucleus test. Mutat. Res. 680: 2-6.

Zhanfen, Q. and Xiaobai, X. 2006. Application of Xenopus laevis in ecotoxicology (I). Introduction and quality control of laboratory animal. Chin. Sci. Bull. 51: 1273-1280.

Zhou, Q., Zhang, J., Fu, J., Shi, J. and Jiang, G. 2008. Biomonitoring: An appealing tool for assessment of metal pollution in the aquatic ecosystem. Anal. Chim. Acta 606: 135-150. 